\title{
The Decline of Employment During COVID-19: The Role of Contact-Intensive Industries
}

Matthew Famiglietti, Research Associate

Fernando Leibovici, Economist

Ana Maria Santacreu, Senior Economist

\section{Introduction}

The ongoing COVID-19 pandemic has had a drastic impact on the labor market, raising the unemployment rate from 3.5 percent in February 2020 to over 10 percent in July (peaking at 14.7 percent in April). This impact, however, has been heterogeneous across industries in the United States. For example, while some industries such as grocery stores have experienced increased demand, the demand for restaurant meals has declined sharply.

Non-essential contact-intensive industries have experienced the largest job losses since the onset of COVID-19.

In a previous post ${ }^{1}$ earlier in the pandemic, we classified industries based on their contact-intensity and documented their importance to the U.S. economy. The idea then was to identify which industries might be most affected by the pandemic. Now that several months have passed, we investigate the extent to which contact-intensive industries have indeed experienced greater job losses than their non-contactintensive counterparts. ${ }^{2}$

\section{Data}

To do so, we follow our methodology from a previous blog post. ${ }^{3}$ That is, we combine individual-level data from the 2017 American Community Survey with an index of occupational contact intensity from $\mathrm{O}^{\star} \mathrm{NET}$ for workers 25-64 years of age. The physical proximity index from $\mathrm{O}^{\star}$ NET quantifies the extent to which different occupations require physical proximity for work to be carried out. ${ }^{4}$

We use these merged datasets to measure contactintensity across industries (from the North American Industry Classification System [NAICS]). We define industries that have an average physical proximity index over 60 to be contact intensive. We merge these industry-level
Figure 1

Employment Dynamics by Industry Category, February-June 2020

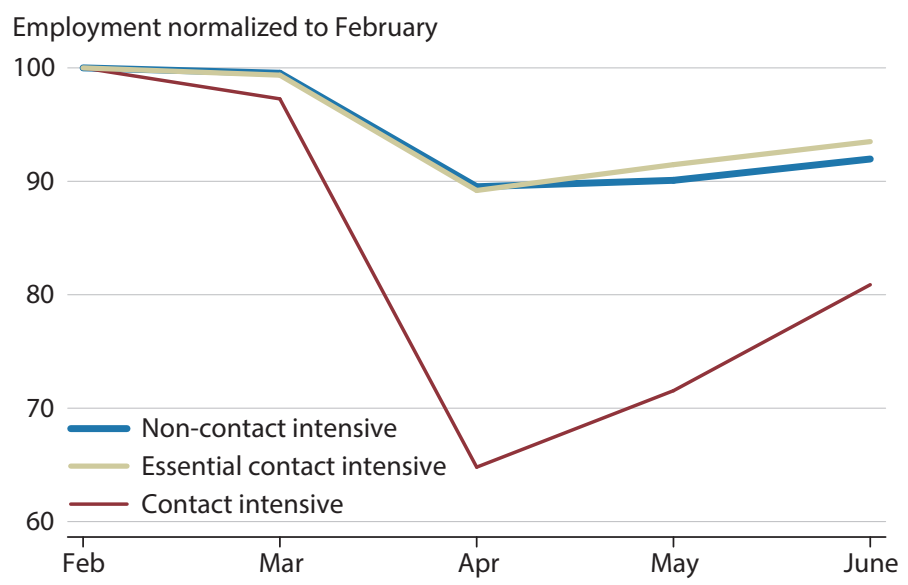

NOTE: The raw data used to plot the figure is available here.

SOURCE: Bureau of Labor Statistics, American Community Survey, O*NET.

measures of contact intensity with monthly employment numbers by industry from the Bureau of Labor Statistics (BLS) to measure how employment losses have differed across industries based on contact intensity.

Given that some industries have been classified as essential and encouraged to remain open, we partition contact-intensive industries into essential and non-essential. While states have defined essential industries heterogeneously, for the purposes of this post we classify contactintensive industries as essential based on their importance to healthcare, utilities, and the food supply chain; this classification is informed by New York State's classification of essential industries. ${ }^{5}$

\section{Contact-Intensive Industries and Employment Losses}

In Figure 1, we plot the change in employment from February to June 2020 across the following three industry groups under analysis: non-contact-intensive industries, non-essential contact-intensive industries, and essential contact-intensive industries. To contrast the dynamics of 
Figure 2

Employment Loss by Industry, February-May 2020

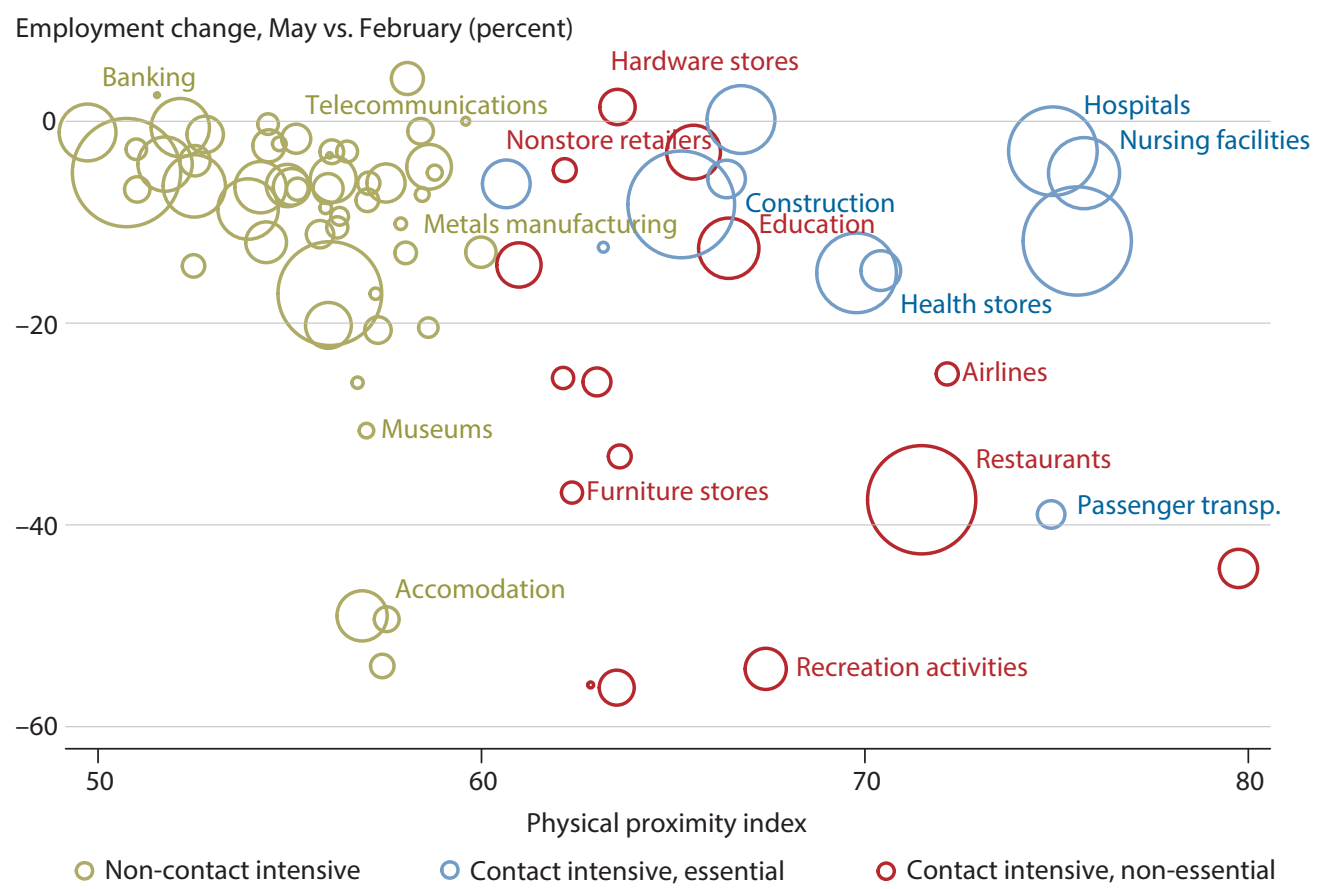

NOTE: The raw data used to plot the figure is available here.

SOURCE: Bureau of Labor Statistics, American Community Survey, O*NET.

employment across these groups, we normalize employment for each category to 100 in February 2020, which allows us to interpret the values for subsequent months as a fraction of employment in February.

We find that, while all industries experienced their largest employment losses in April, non-essential contactintensive industries were the most affected. While noncontact-intensive industries and essential contact-intensive industries contracted by about 10 percent, non-essential contact-intensive industries' employment contracted by about 35 percent relative to that in February. Employment has been recovering in all industry groups since April, but employment levels are not yet close to their pre-pandemic levels.

We complement our previous analysis with a more granular view of industries and employment loss during the pandemic. To do so, we plot in Figure 2 the relationship between the physical proximity index and the employment changes between February and May 2020 across each of the NAICS industries reported by the BLS. ${ }^{6}$

While there is obviously some heterogeneity in the employment losses experienced across industries within each of the industry groups, we find that the overall patterns observed in Figure 1 are largely representative of the typical industries in each group. In particular, we observe that most non-contact-intensive industries and most essential contact-intensive industries experienced moderate employment losses, while most non-essential contact-intensive industries experienced much larger job losses.

The scatter plot moreover allows us to identify the degree to which specific industries have been impacted. For instance, essential contact-intensive industries that are concerned with healthcare, such as hospitals and nursing/ residential care facilities, experienced relatively little change in employment during this period. In contrast, there is some more heterogeneity in the level of job loss across noncontact-intensive industries: Industries such as banking and telecommunications, whose workers are largely able to work from home, have experienced limited job losses, while industries with workers less able to work from home, such as metals manufacturing, have had employment levels decline relatively more. A similar degree of heterogeneity can be observed across non-essential contact-intensive industries.

\section{Conclusion}

We find that differences in contact intensity and the essential nature of goods and services play significant roles in accounting for the heterogeneous employment losses experienced across U.S. industries. Yet, this analysis abstracts 
from other dimensions that could further help to identify key factors underlying the large employment losses experienced during COVID-19: For example, the degree to which jobs can be done from home and the heterogeneous exposure to the virus given that different states have differential exposure to industries might further account for differences in employment changes across industries during this period.

\section{Notes}

1 Leibovici, Fernando; Santacreu, Ana Maria and Famiglietti, Matthew. "How the Impact of Social Distancing Ripples through the Economy." St. Louis Fed On the Economy Blog, April 7,2020; https://www.stlouisfed.org/on-the-economy/2020/april/impact-social-distancing-ripples-economy.

2 We thank Andy Neumeyer for helpful discussions.

3 Leibovici, Fernando; Santacreu, Ana Maria and Famiglietti, Matthew. "Social Distancing and Contact-Intensive Occupations." St. Louis Fed On the Economy Blog, March 24, 2020; https://www.stlouisfed.org/on-the-economy/2020/ march/social-distancing-contact-intensive-occupations.

${ }^{4} \mathrm{~A}$ measure of 100 would imply a worker is always within close proximity to other people, whereas a measure of 0 would imply the opposite.

${ }^{5}$ We classify the following industries as essential: Building material and garden supply stores; Transit and ground passenger transportation; Social assistance; Health and personal care stores; Water transportation; Ambulatory health care services; Construction; Truck transportation; Gasoline stations; Nursing and residential care facilities; Hospitals; and Food and beverage stores.

${ }^{6}$ The sizes of the circles in Figure 2 are proportional to industries' employment in February 2020. 
